\title{
Endoplasmic reticulum stress induces ligand-independent TNFR1-mediated necroptosis in L929 cells
}

\author{
S Saveljeva ${ }^{1,2}$, SL Mc Laughlin ${ }^{1,2}$, P Vandenabeele ${ }^{3,4}$, A Samali, ${ }^{*, 1,2,5}$ and MJM Bertrand ${ }^{\star, 3,4,5}$
}

Endoplasmic reticulum (ER) stress-induced cellular dysfunction and death is associated with several human diseases. It has been widely reported that ER stress kills through activation of the intrinsic mitochondrial apoptotic pathway. Here we demonstrate that ER stress can also induce necroptosis, an receptor-interacting protein kinase 1 (RIPK1)/RIPK3/mixed lineage kinase domain-like protein (MLKL)-dependent form of necrosis. Remarkably, we observed that necroptosis induced by various ER stressors in L929 cells is dependent on tumor necrosis factor receptor 1 (TNFR1), but occurs independently of autocrine TNF or lymphotoxin $\alpha$ production. Moreover, we found that repression of either TNFR1, RIPK1 or MLKL did not protect the cells from death but instead allowed a switch to ER stress-induced apoptosis. Interestingly, while caspase inhibition was sufficient to protect TNFR1- or MLKL-deficient cells from death, rescue of the RIPK1-deficient cells additionally required RIPK3 depletion, indicating a switch back to RIPK3-dependent necroptosis in caspase-inhibited conditions. The finding that ER stress also induces necroptosis may open new therapeutic opportunities for the treatment of pathologies resulting from unresolved ER stress.

Cell Death and Disease (2015) 6, e1587; doi:10.1038/cddis.2014.548; published online 8 January 2015

The endoplasmic reticulum (ER) has a major role in the synthesis, folding and trafficking of secretory and membrane proteins. ${ }^{1}$ Many cellular conditions can alter proper ER functions. As a consequence, un- or misfolded proteins accumulate in the ER lumen and induce ER stress. All eukaryotic cells have developed a quality control system, known as the unfolded protein response (UPR), to sense and adapt to ER stress. ${ }^{2}$ In mammalian cells, the UPR emerges from three ER-anchored receptors (inositol-requiring enzyme1 (IRE1), protein kinase RNA-like ER kinase (PERK) and activating transcription factor 6 ) and promotes a return to ER homeostasis by activating signaling pathways aimed at increasing the folding capacity of the ER, reducing synthesis of new proteins and promoting alternative forms of protein degradation (such as ER-associated degradation and autophagy). However, when ER stress is too severe and/or prolonged, the UPR is insufficient to restore homeostasis, and therefore turns into a toxic signal leading to cell death., ${ }^{3,4}$ Accumulating evidence indicate that ER stress-induced cellular dysfunction and death are associated with and contribute to several human diseases (such as neurodegenerative diseases, inflammation and cancer), highlighting the need for a better understanding of the molecular mechanisms regulating ER stress-mediated death in the hope to identify new therapeutic targets..$^{5-7}$
ER stress is widely reported to induce caspase-dependent apoptotic cell death, and although few studies support implication of the receptor extrinsic pathway, the vast majority of them attribute the killing to the activation of the mitochondrial intrinsic pathway. ${ }^{4}$ The intrinsic apoptotic pathway relies on the B-cell lymphoma 2 (BCL-2)-associated X protein/BCL-2 antagonist/killer-dependent mitochondrial outer membrane permeabilization (MOMP), which causes the release of cytochrome $c$ into the cytoplasm and allows formation of the apoptosome and the subsequent activation of procaspase-9. Distinct mechanisms have been reported to induce MOMP by modulating the expression and/or activation of the various pro- and anti-death BCL-2 family members in conditions of unresolved ER stress. ${ }^{8}$ Among them are the IRE1-mediated C-Jun N-terminal kinase (JNK) activation, ${ }^{9}$ the controversial IRE1-dependent degradation of caspase-2 targeting miRNA ${ }^{10,11}$ or the PERK-dependent expression of the transcription factor $\mathrm{C} /$ EBP-homologous protein (CHOP). ${ }^{12,13}$

Apoptosis is however not the only way for a cell to die, and recent studies have highlighted the importance of necroptosis, a regulated form of necrosis that relies on the enzymatic activity of the serine/threonine receptor-interacting protein kinase 1 (RIPK1) and RIPK3, in the pathogenesis of various human diseases. ${ }^{14,15}$ Necroptosis has so far mainly been studied in the context of death receptor signaling, such as downstream of the tumor necrosis factor (TNF) receptor 1

\footnotetext{
${ }^{1}$ Apoptosis Research Center, National University of Ireland, Galway, Ireland; ${ }^{2}$ School of Natural Sciences, National University of Ireland, Galway, Ireland; ${ }^{3} \mathrm{VIB}$ Inflammation Research Center (IRC), Technologiepark 927, Zwijnaarde-Gent 9052, Belgium and ${ }^{4}$ Department of Biomedical Molecular Biology, VIB/Ghent University, Technologiepark 927, Zwijnaarde-Gent 9052, Belgium

*Corresponding authors: A Samali, Apoptosis Research Centre, Biosciences, Newcastle Road, Dangan, NUI Galway, Ireland. Tel: +353 91492440; Fax: +353 91494596; E-mail: afshin.samali@nuigalway.ie

or MJM Bertrand, VIB Inflammation Research Center (IRC), VIB/Ghent University, Technologiepark 927, Zwijnaarde-Gent 9052, Belgium. Tel: +32 93313720 ; Fax: +32 9 3313511; E-mail: mathieu.bertrand@irc.vib-ugent.be

${ }^{5}$ These are co-senior authors.

Abbreviations: BCL-2, B-cell lymphoma 2; CHOP, C/EBP-homologous protein; ER, endoplasmic reticulum; IRE1, inositol-requiring enzyme-1; JNK, c-Jun $\mathrm{N}$-terminal kinase; LT $\alpha$, lymphotoxin $\alpha$; MOMP, mitochondrial outer membrane permeabilization; MLKL, mixed lineage kinase domain-like protein; PERK, protein kinase RNA-like ER kinase; RIPK, receptor-interacting protein kinase; TNF, tumor necrosis factor; UPR, unfolded protein response

Received 25.8.14; revised 31.10.14; accepted 12.11.14; Edited by G Raschellà
} 
(TNFR1), and was shown to prevail in caspase-8-inhibited conditions. ${ }^{16-18}$ In contrast to most cells, the murine fibrosarcoma L929 cells do not require caspase inhibition to undergo TNF-mediated necroptosis, rendering these cells of particular interest for the in vitro study of necroptosis. Nevertheless, L929 cells retain the ability to undergo apoptosis, and switches to TNFmediated apoptosis have been reported when components of the necroptotic machinery are repressed, ${ }^{19,20}$ L929 cells also activate the intrinsic apoptotic pathway when stimulated with apoptosis-inducing agents such as staurosporine. ${ }^{21}$

In this study, we investigated the cell death modality induced by sustained ER stress in the L929 cell line, a cellular model for both apoptosis and necroptosis induction. In these cells, we found that ER stress induction by chemical triggers such as brefeldin $\mathrm{A}$, thapsigargin and tunicamycin did not activate the intrinsic apoptotic pathway but instead triggered TNFR1mediated necroptosis. Remarkably, TNFR1 signaling was independent of the autocrine production of the receptor's cognate ligands TNF and lymphotoxin $a$ (LTa). In addition, we found that chemical inhibition of RIPK1 kinase activity by necrostatin-1 ( $\mathrm{Nec}-1)$ protected the cells from death, while repressing RIPK1, mixed lineage kinase domain-like protein (MLKL) or TNFR1 levels induced a switch in the cell death modality, from necroptosis to apoptosis. Taken together, these results highlight the ability of ER stress to trigger cell death modalities other than apoptosis, and identified Nec-1 as a potential new compound for the treatment of pathologies resulting from unresolved ER stress-mediated death.

\section{Results}

ER stress induces caspase-independent necroptosis in L929sA cells. To determine the cell death modality induced by sustained ER stress in the L929sA cell line, we stimulated the cells with three different compounds reported to be strong inducers of ER stress, namely brefeldin A, thapsigargin and tunicamycin. ER stress induction by these compounds was confirmed by monitoring the expression of several ER stress markers, such as spliced XBP-1, Grp78 and CHOP (Supplementary Figure S1). We observed that each compound triggered death of the L929sA cells in a dose-dependent manner (Figures 1a-c), and that $\sim 30-50 \%$ of cell death was obtained after $24 \mathrm{~h}$ of stimulation with the different compounds used at the respective concentration of $0.5 \mu \mathrm{g} / \mathrm{ml}, 2.5 \mu \mathrm{M}$ and $2.5 \mu \mathrm{g} / \mathrm{ml}$ (Figure 1d). A comparable amount of cell death was obtained by stimulating the cells with either $30 \mathrm{ng} / \mathrm{ml}$ of TNF for $4 \mathrm{~h}$ or with $10 \mathrm{nM}$ of staurosporine for $24 \mathrm{~h}$, two triggers, respectively, used as positive controls for necroptosis and apoptosis induction in these cells (Figures 1e and f). To evaluate whether the death induced by the different ER stressors was relying on caspase activation, we monitored processing of caspase- 9 and -3 as well as cleavage of the caspase- 3 substrate PARP by immunoblotting cell lysates obtained after stimulating the cells with $0.5 \mu \mathrm{g} / \mathrm{ml}$ of brefeldin $\mathrm{A}, 2.5 \mu \mathrm{M}$ of thapsigargin and $2.5 \mu \mathrm{g} / \mathrm{ml}$ of tunicamycin over a period of $24 \mathrm{~h}$. Similarly to TNF stimulation and contrary to staurosporine treatment, none of the ER stress inducers lead to caspase activation (Figure 1g), which was confirmed by DEVDase assays performed on lysates collected $24 \mathrm{~h}$ after stimulation (Figure 1h). In line with these results, pre-treatment with the pancaspase inhibitor Boc-D-FMK protected the cells from staurosporine-mediated killing but not from brefeldin A- or TNF-induced death (Figure 1i). To test whether the caspase-independent death caused by the administration of the ER stressors could result from necroptosis induction, we next evaluated the potential protective effect of inhibiting RIPK1 kinase activity with $\mathrm{Nec}-1$. As shown in Figure 1j, RIPK1 kinase inhibition protected L929sA cells from brefeldin A-induced death as efficiently as following TNF stimulation, but had no effect on staurosporine-mediated killing. We confirmed these results using the more stable and specific RIPK1 inhibitor, Nec-1s (Supplementary Figure S2). Taken together, these results demonstrate that ER stress induces RIPK1 kinase-dependent necroptosis in L929 cells.

RIPK1 repression shifts ER stress-induced necroptosis to ER stress-induced apoptosis. To further characterize the role of RIPK1 during ER stress-induced death, we stably repressed RIPK1 expression in L929sA cells. Surprisingly, and in contrast to the Nec-1 effect, we found that RIPK1 knockdown did not protect the cells from brefeldin A-mediated death (Figure 2a). In the context of TNF signaling, we previously reported that, contrary to Nec-1, RIPK1 repression does not protect L929sA cells from TNF cytotoxicity but instead sensitized them by allowing a switch from necroptotic to apoptotic death. ${ }^{19,20}$ We therefore wondered whether a similar mechanism was occurring upon ER stress induction. To test this hypothesis, we monitored caspase activation by immunoblot and DEVDase assays in lysates of control and RIPK1-depleted L929sA cells stimulated with brefeldin A, or TNF used as a control. We found that RIPK1 knockdown resulted in the induction of caspase activation both following TNF and brefeldin A stimulation (Figures $2 \mathrm{~b}$ and $\mathrm{c}$ ). Interestingly, although Boc-D-FMK was very efficient in inhibiting caspase activation (Figure $2 b$ ), it did not protect RIPK1-depleted cells from brefeldin A treatment and only had a limited protective effect following TNF stimulation (Figure 2a). Because a switch back to RIPK3dependent necroptosis was reported in RIPK1-depleted L929sA cells stimulated with TNF in the presence of caspase-8 repression, ${ }^{19}$ we next investigated the effect of additional RIPK3 depletion on the death of RIPK1-repressing cells stimulated with brefeldin A and Boc-D-FMK. As shown in Figures $2 d$ and e, additional RIPK3 depletion did not protect RIPK1-depleted L929sA cells from brefeldin A used alone but greatly rescued them under caspase-inhibited conditions. As expected, RIPK3 knockdown also provided further protection to the RIPK1-depleted L929sA cells stimulated with TNF and Boc-D-FMK (Figure 2d). Taken together, these results highlight the high similarities in the death pathways activated by TNF and ER stress inducers in L929sA cells.

MLKL serves as an effector of ER stress-induced necroptosis. MLKL recently emerged as a key molecule mediating necroptosis downstream of RIPK3. ${ }^{22-25}$ To test whether MLKL has a role in necroptosis triggered by $E R$ stress inducers in L929sA cells, we transfected the cells with 
a

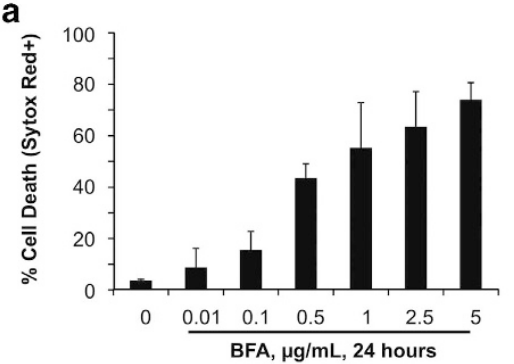

d

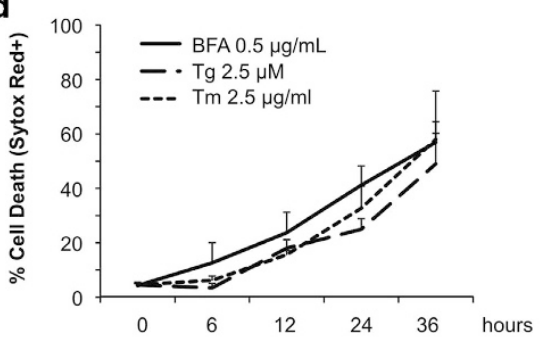

b

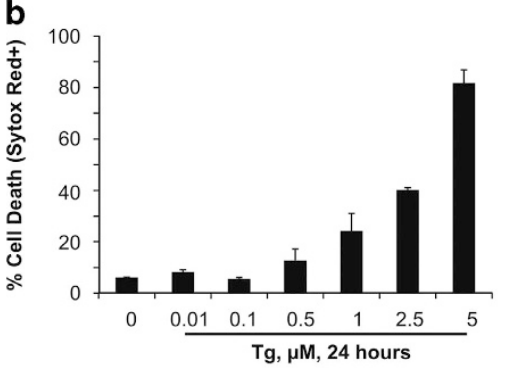

e

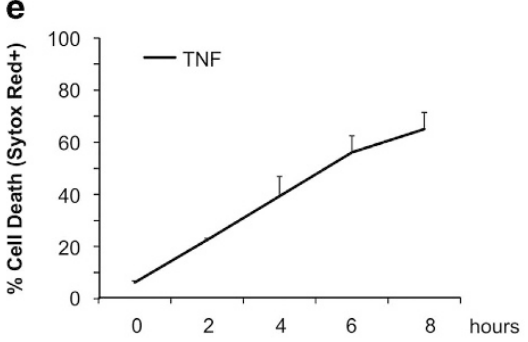

C

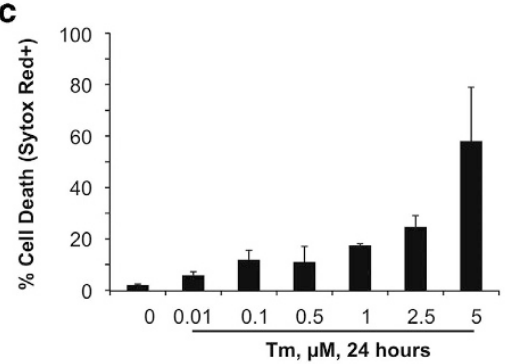

f
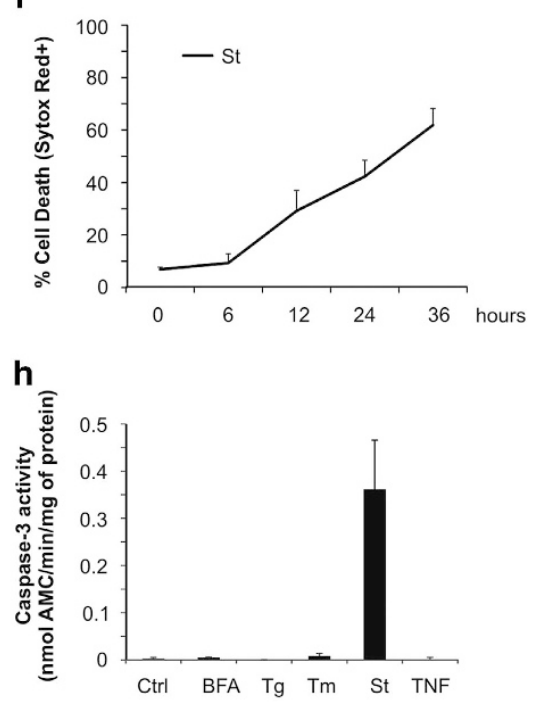

g
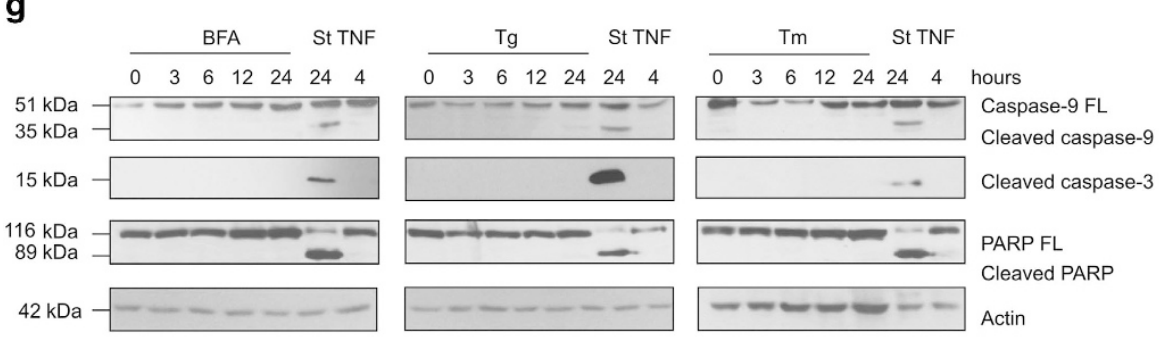

i

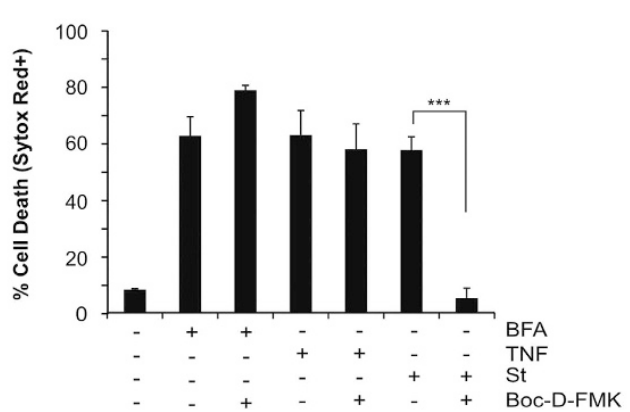

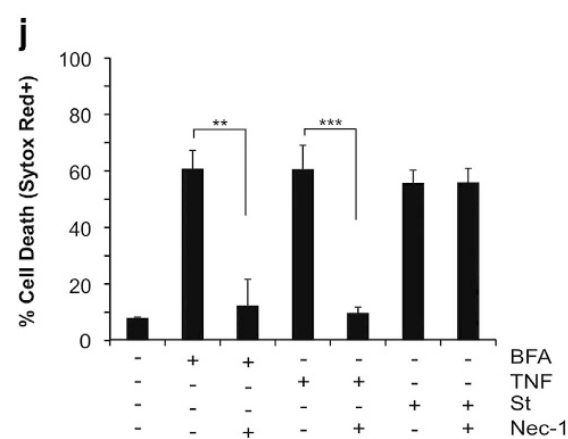

Figure 1 ER stress induces necroptosis in L929sA cells. (a-f) L929sA cells were treated with increasing concentrations of brefeldin A (BFA) (a), thapsigargin (Tg) (b) and tunicamycin (Tm) (c) for $24 \mathrm{~h}$, with $0.5 \mu \mathrm{g} / \mathrm{ml}$ of BFA, $2.5 \mu \mathrm{M}$ of Tg and $2.5 \mu \mathrm{g} / \mathrm{ml}$ of Tm over a period of $36 \mathrm{~h}$ (d) or with $30 \mathrm{ng} / \mathrm{ml}$ of human TNF (hTNF) (e) up to $8 \mathrm{~h}$ or with $10 \mathrm{~nm}$ of staurosporine (St) up to $36 \mathrm{~h} \mathrm{(f),} \mathrm{and} \mathrm{the} \mathrm{percentage} \mathrm{of} \mathrm{cell} \mathrm{death} \mathrm{was} \mathrm{determined} \mathrm{by} \mathrm{flow} \mathrm{cytometry} \mathrm{following} \mathrm{Sytox} \mathrm{Red} \mathrm{staining.} \mathrm{(g)} \mathrm{Immunoblots} \mathrm{of} \mathrm{cell} \mathrm{lysates} \mathrm{isolated}$ following treatment with $0.5 \mu \mathrm{g} / \mathrm{ml}$ of BFA, $2.5 \mu \mathrm{g} / \mathrm{ml}$ of Tm and $2.5 \mu \mathrm{M}$ of Tg for the indicated period, as well as with $10 \mathrm{nM}$ of St ( $24 \mathrm{~h}$ ) and $30 \mathrm{ng} / \mathrm{ml}$ of hTNF (4 h). (h) Caspase-3 activity measured by DEVD-AMC assay after $24 \mathrm{~h}$ of treatment with $0.5 \mu \mathrm{g} / \mathrm{ml}$ of BFA, $2.5 \mu \mathrm{g} / \mathrm{ml}$ of Tm and $2.5 \mu \mathrm{M}$ of Tg, as well as after $24 \mathrm{~h}$ with $10 \mathrm{nM}$ of St and $4 \mathrm{~h}$ with $30 \mathrm{ng} / \mathrm{ml}$ of hTNF. (i and j) Cell death evaluated by flow cytometry after Sytox Red staining of L929sA stimulated with $0.5 \mu \mathrm{g} / \mathrm{ml}$ of BFA ( $24 \mathrm{~h}), 10 \mathrm{nM}$ of St $(24 \mathrm{~h})$ and $30 \mathrm{ng} / \mathrm{ml}$ of $\operatorname{hTNF}(4 \mathrm{~h})$ in the absence and presence of $10 \mu \mathrm{M}$ of Boc-D-FMK (i) or $20 \mu \mathrm{M}$ of Nec-1 (j). PARP, poly-ADP ribose polymerase

MLKL or control siRNA (Figure 3a) and monitored cell viability upon BFA treatment. Interestingly, MLKL repression also resulted in a switch from necroptosis to apoptosis, which was observed by the loss of protective effect of $\mathrm{Nec}-1$ and the gain of protection offered by Boc-D-FMK (Figure 3b). Therefore, contrary to RIPK1, MLKL repression did not allow a switch back to RIPK3-dependent necroptosis in caspaseinhibited conditions. The switch to apoptosis was confirmed by the analysis of caspase- 9 and -3 processing by western blot (Figure 3c). As reported previously, ${ }^{20}$ we observed that
MLKL repression also induced a switch to apoptosis when stimulating L929sA cells with TNF. Taken together, these results further support activation of the same necroptotic cascade between TNF stimulation and ER stress induction in these cells.

TNFR1 mediates ER stress-induced necroptosis. Owing to the strong similarities in the killing of L929sA cells by TNF and ER stress inducers, we wondered whether the death induced by ER stress in these cells would not actually be 

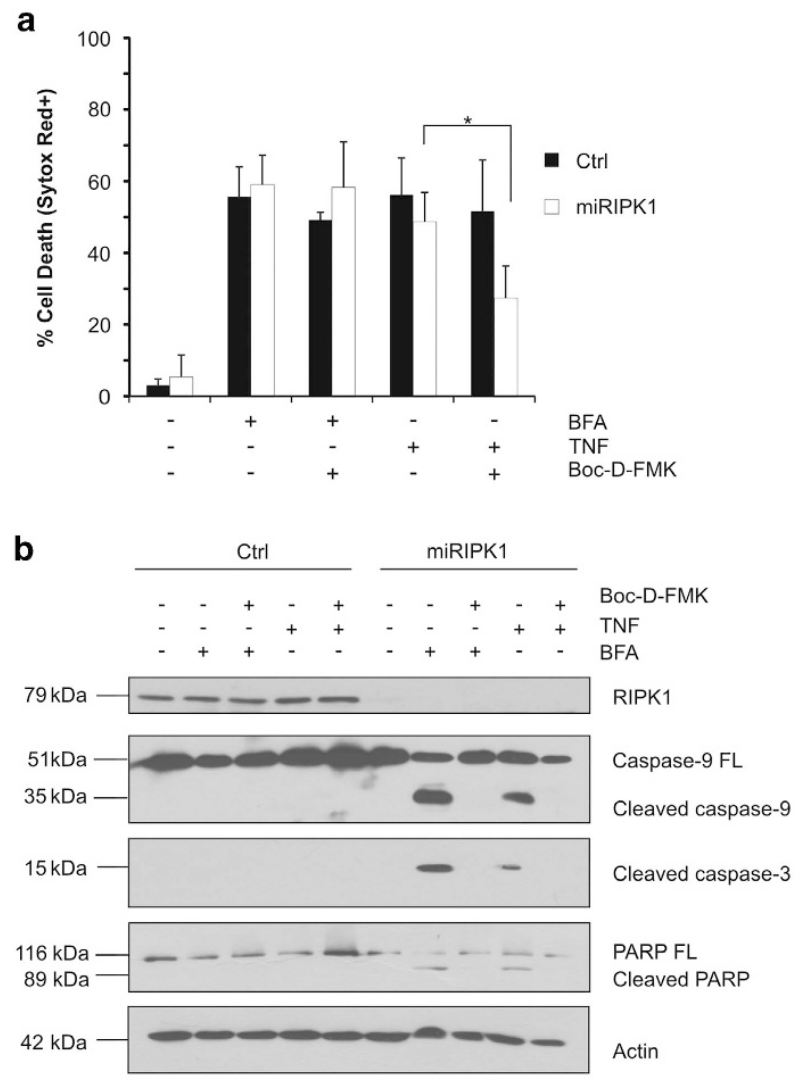

C
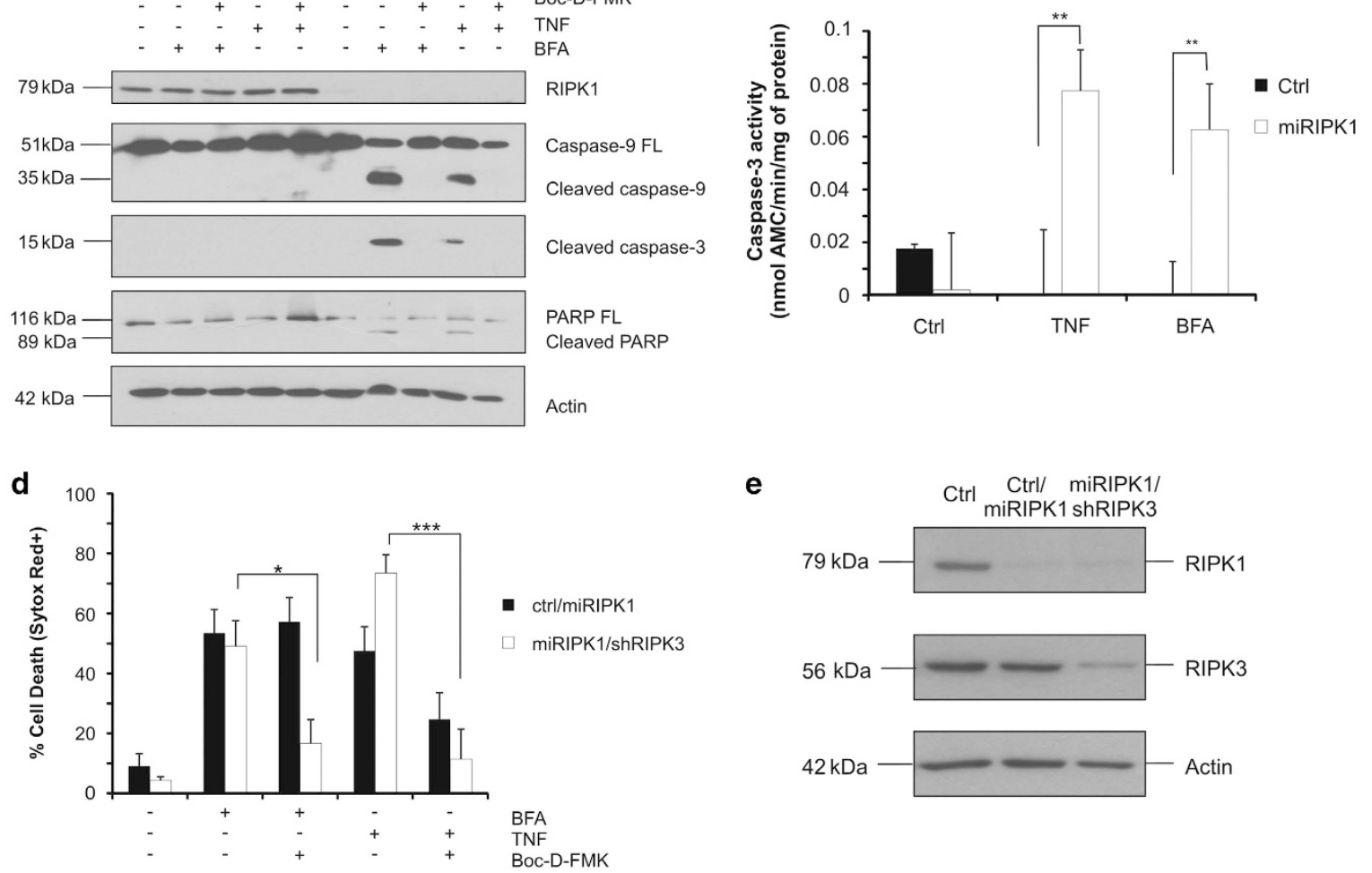

e
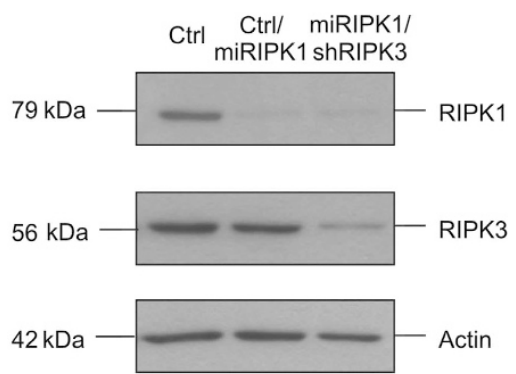

Figure 2 RIP1K1 repression shifts ER stress-induced necroptosis to ER stress-induced apoptosis. (a) Control (Ctrl) and RIPK1-depleted (miRIPK1) L929sA cells were treated for $24 \mathrm{~h}$ with $0.5 \mu \mathrm{g} / \mathrm{ml}$ of brefeldin A (BFA) or $2-4 \mathrm{~h}$ with $30 \mathrm{ng} / \mathrm{ml}$ of human TNF (hTNF) (Ctrl cells were stimulated for $4 \mathrm{~h}$ and RIPK1-depleted cells for $2 \mathrm{~h}$ to induce a comparable amount of cell death), alone or in combination with $10 \mu \mathrm{M}$ of Boc-D-FMK, and viability was evaluated by flow cytometry following Sytox Red staining. (b) Immunoblots of cell lysates of Ctrl and RIPK1-depleted L929sA cells isolated following treatment for $24 \mathrm{~h}$ with $0.5 \mu \mathrm{g} / \mathrm{ml}$ of BFA or $2-4 \mathrm{~h}$ with $30 \mathrm{ng} / \mathrm{ml}$ of hTNF (Ctrl cells were stimulated for $4 \mathrm{~h}$ and RIPK1-depleted cells for $2 \mathrm{~h}$ to induce a comparable amount of cell death), alone or in combination with $10 \mu \mathrm{M}$ of Boc-D-FMK. (c) Caspase-3 activity in Ctrl and RIPK1depleted L929sA cells measured by DEVD-AMC assay after $24 \mathrm{~h}$ of treatment with $0.5 \mu \mathrm{g} / \mathrm{ml}$ of BFAA as well as after $2-4 \mathrm{~h}$ of treatment with $30 \mathrm{ng} / \mathrm{ml}$ of hTNF (Ctrl cells were stimulated for $4 \mathrm{~h}$ and RIPK1-depleted cells for $2 \mathrm{~h}$ to induce a comparable amount of cell death). (d) RIPK1-depleted (Ctr//miRIPK1) and RIPK1/RIPK3-depleted (miRIPK1/ shRIPK3) L929sA cells were treated for $24 \mathrm{~h}$ with $0.5 \mu \mathrm{g} / \mathrm{ml}$ of BFA alone or in combination with $10 \mu \mathrm{M}$ of Boc-D-FMK, and the cell viability was evaluated by flow cytometry after Sytox Red staining. Cells were also treated with $30 \mathrm{ng} / \mathrm{ml}$ of hTNF (2 h). (e) Lysates from Ctrl and RIPK1- and RIPK1/RIPK3-depleted L929sA cells probed for RIPK1 and RIPK3 to validate the efficiency of the knockdowns. Actin was used as a loading control. PARP, poly-ADP ribose polymerase

mediated by TNF itself. Previous studies have indeed reported NF-kB-mediated autocrine production of TNF upon ER stress induction in certain cells. ${ }^{26}$ We therefore first evaluated this possibly by testing the effect of TNFR1 repression on ER stress-induced death. Although not complete, the extent of TNFR1 knockdown that we obtained was sufficient to protect the cells from TNF-induced necroptosis, but had no significant protective effect on brefeldin A cytotoxicity (Figures 4a and b). Nevertheless, the finding that Nec-1 had lost its protective effect in these cells raised the possibility of a switch to another, RIPK1 kinaseindependent, cell death modality (Figure 4a). This assumption was confirmed when analyzing caspase activation by immunoblot and DEVDase assays. We observed that TNFR1 repression induced a switch from RIPK1 kinase activity-dependent necroptosis to RIPK1 kinase-independent 
a

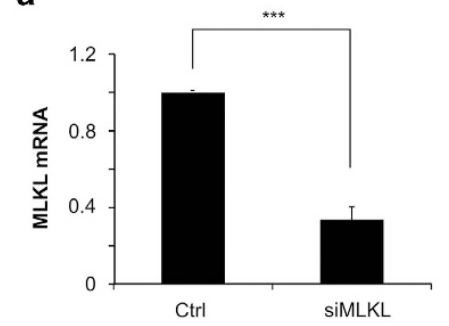

C $\quad \frac{\text { Ctrl }}{- \text { TNF BFA }} \frac{\text { simLKL }}{- \text { TNF BFA }}$

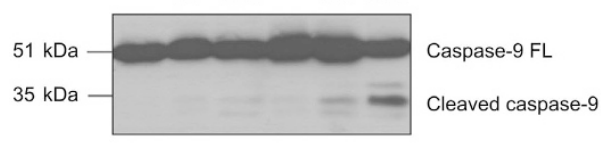

$15 \mathrm{kDa}-\longrightarrow$ Cleaved caspase-3

$42 \mathrm{kDa}-\longrightarrow$ Actin b

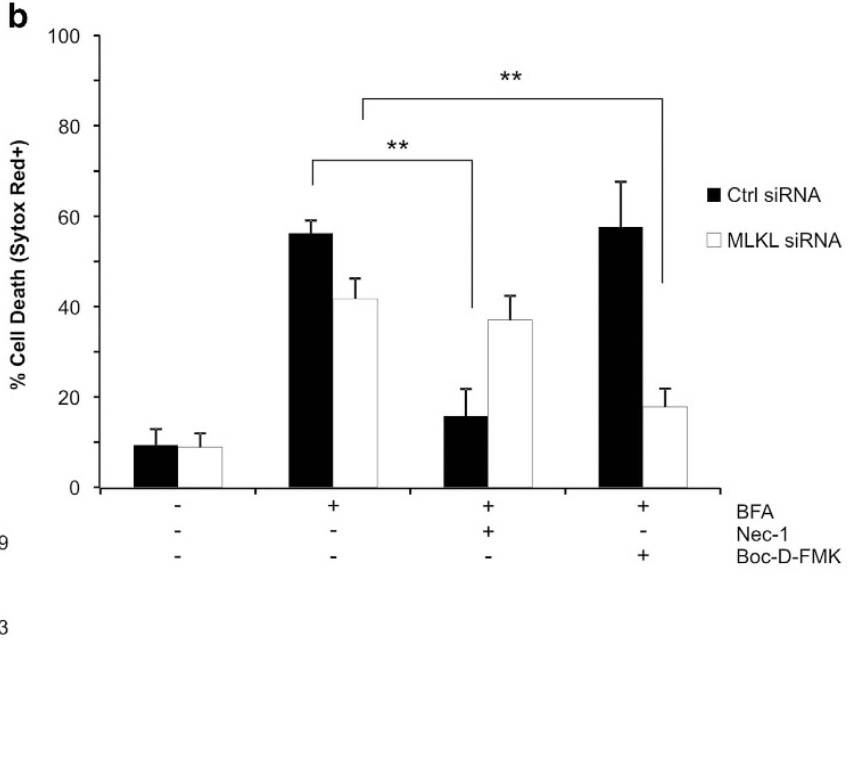

Figure 3 Role of MLKL in ER stress-induced necroptosis. (a) Levels of MLKL mRNA after short interfering RNA (siRNA)-mediated knockdown. (b) L929sA cells were treated for $24 \mathrm{~h}$ with $0.5 \mu \mathrm{g} / \mathrm{ml}$ of brefeldin A (BFA) alone or in combination with $20 \mu \mathrm{M}$ of Nec-1 or $10 \mu \mathrm{M}$ of Boc-D-FMK, and viability was evaluated by flow cytometry following Sytox Red staining. (c) L929sA cells transfected with control (Ctrl) and MLKL siRNAs were lysed after treatment for $24 \mathrm{~h}$ with $0.5 \mu \mathrm{g} / \mathrm{ml}$ of BFA or with $30 \mathrm{ng} / \mathrm{ml}$ of human TNF (hTNF) (4 h) and expression of apoptotic markers was analyzed by western blot

apoptosis following ER stress induction by brefeldin $\mathrm{A}$ or thapsigargin treatment (Figures 4c-e). Importantly, the apoptotic cell death was fully prevented when costimulating the TNFR1-repressing cells with the caspase inhibitor Boc-DFMK (Figure 3a). These findings therefore demonstrate that TNFR1 is the upstream mediator of necroptosis in L929sA cells undergoing unresolved ER stress, and illustrate the ability of these cells to still switch to apoptosis when TNFR1 signaling is inhibited at the level of the receptor itself.

TNFR1 mediates ER stress-induced necroptosis independently of ligand binding. Having established that ER stress kills L929 cells by triggering TNFR1-mediated necroptosis, we next examined whether the killing was occurring as a result of autocrine TNF production. To do so, we first analyzed by ELISA the ability of L929sA cells to secrete soluble TNF following ER stress induction. We found that stimulation with brefeldin A over a period of $24 \mathrm{~h}$ did not induce detectable levels of soluble TNF in the cell medium (Figure 5a). By contrast, LPS stimulation, a known inducer of TNF secretion, leads to detectable amounts of TNF in the medium (Figure 5a). To further exclude a role of extracellular TNF, we next incubated the cells with a TNFblocking antibody before ER stress induction. As shown in Figure 5b, the addition of the TNF-blocking antibody did not affect brefeldin A or thapsigargin cytotoxicity, but efficiently blocked cell death induced by exogenous TNF. Because export of secreted proteins is most probably greatly affected under severe ER stress conditions, we hypothesized that activation of TNFR1 by its ligands could alternatively occur in intracellular compartments. Apart from TNF, lymphotoxin a (LTa) was recently reported to be as potent as TNF in mediating apoptosis, necroptosis and inflammatory signals. $^{27}$ We therefore analyzed the transcriptional upregulation of the genes encoding these two TNFR1 ligands by Q-PCR analysis. As shown in Figure $5 c$, brefeldin $A$ treatment resulted in the upregulation of both TNF and LTa mRNA transcripts, and therefore still supporting a potential role of their encoded proteins in ER stressinduced death. We then analyzed the effect of repressing TNF and LTa on the killing potential of brefeldin A. The efficacy of TNF and LTa knockdown was confirmed at the mRNA level by Q-PCR (Figure $5 \mathrm{~d}$ ) and at the protein level by western blotting for TNF (Figure $5 f$ ). We found that TNF and LTa repression had no effect on brefeldin A cytotoxicity when compared with nonspecific siRNA treatment (Figure 5e). Importantly, we confirmed that the lack of protective effect was not due to a switch to RIPK1 kinaseindependent apoptosis, as observed upon TNFR1 repression. Indeed, contrary to TNFR1-depleted cells (Figure 4), brefeldin A treatment did not induce caspase activation in the TNF- and LTa-depleted cells (Figure 5f). Accordingly, these cells were still protected by Nec-1, while Boc-D-FMK had no effect on their viability (Figure $5 e$ ). These results clearly demonstrate that ER stress induces TNFR1mediated necroptosis in L929sA cells independently of ligand binding.

Role of the JNK pathway in ER stress-mediated cell death. It has previously been suggested that ER stress could kill by activating a TRAF2/JNK pathway, ${ }^{2}$ and that RIPK1 was required for JNK activation by interacting with TNFR1. ${ }^{28}$ Knowing the contribution of JNK to both apoptotic $^{29}$ and caspase-independent mode of cell death, ${ }^{30}$ we therefore evaluated the role of the JNK pathway in our cellular model. To do so, we applied SP600125, an inhibitor of JNK-1, -2 and $-3,{ }^{31}$ in combination with BFA or TNF treatment in L929sA cells and evaluated its effect on the viability of the 


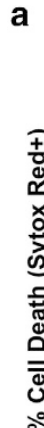

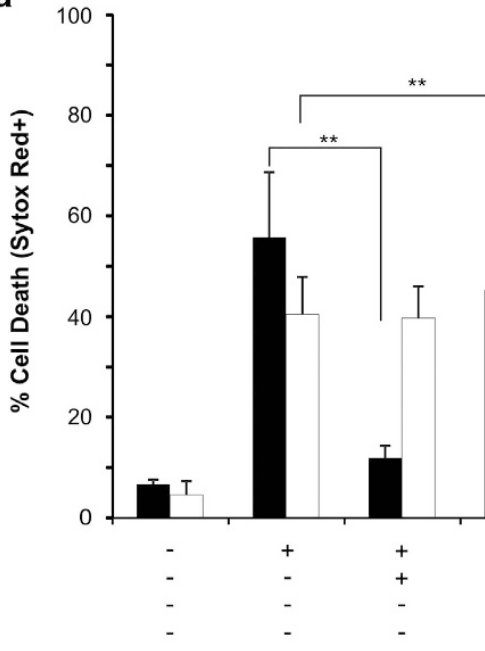

C
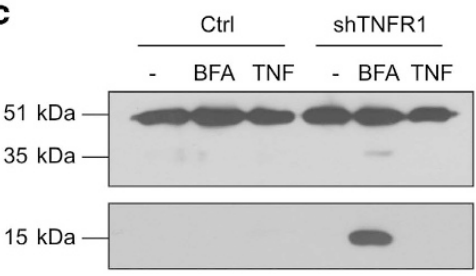

$116 \mathrm{kDa}-\longrightarrow-\ldots$

$89 \mathrm{kD}$

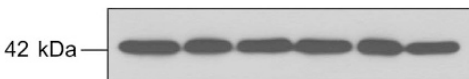

Caspase-9 FL

Cleaved caspase- 9

Cleaved caspase-3

PARP FL

Cleaved PARP

Actin

e
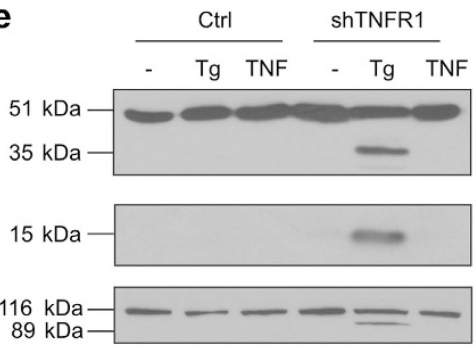

$42 \mathrm{kDa}-----$

Caspase-9 FL

Cleaved caspase-9

Cleaved caspase-3

PARP FL

Cleaved PARP

Actin b

Ctrl shTNFR1

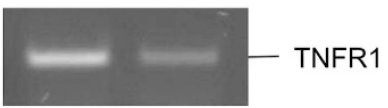

- Ctrl

$\square$ shTNFR1

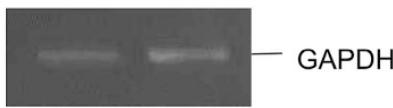

BFA
Nec-1
Boc-D-FMK
TNF

d

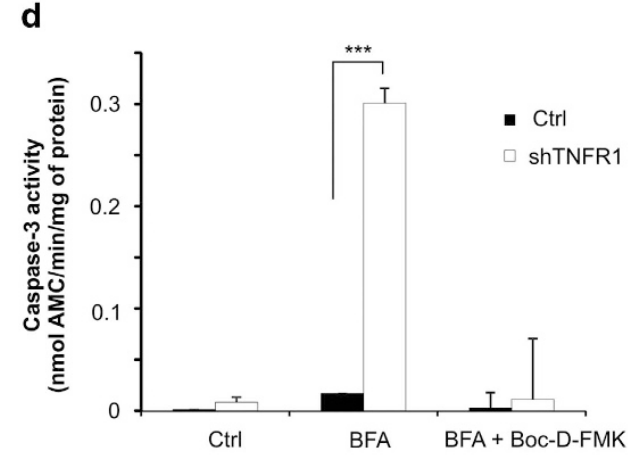

Figure 4 Involvement of TNFR1 in ER stress induced cell death. (a) Control (Ctrl) and TNFR1-depleted (shTNFR1) L929sA cells were treated for $24 \mathrm{~h}$ with $0.5 \mu \mathrm{g} / \mathrm{ml}$ of brefeldin $\mathrm{A}$ (BFA) alone or in combination with $20 \mu \mathrm{M}$ of Nec-1 or $10 \mu \mathrm{M}$ of Boc-D-FMK, and viability was evaluated by flow cytometry following Sytox Red staining. Functionality of the knockdown was confirmed after treatment with human TNF (hTNF). (b) Knockdown of TNFR1 was validated by reverse transcription-PCR (RT-PCR) with specific primers. Glyceraldehyde 3-phosphate dehydrogenase (GAPDH) was used as an endogenous control. (c) Immunoblots of Ctrl and TNFR1-depleted L929sA cells lysates isolated after treatment for $24 \mathrm{~h}$ with $0.5 \mu \mathrm{g} / \mathrm{ml}$ of BFA or with $30 \mathrm{ng} / \mathrm{ml}$ of hTNF (4 h). (d) Caspase-3 activity in Ctrl and TNFR1-depleted L929sA cells measured by DEVD-AMC assay after $24 \mathrm{~h}$ of treatment with $0.5 \mu \mathrm{g} / \mathrm{ml}$ of BFA alone or in combination with $10 \mu \mathrm{M}$ of Boc-D-FMK. (e) Immunoblots of Ctrl and TNFR1-depleted L929sA cell lysates isolated after treatment for $24 \mathrm{~h}$ with $2.5 \mu \mathrm{M}$ of thapsigargin $(\mathrm{Tg})$ or with $30 \mathrm{ng} / \mathrm{ml}$ of hTNF (4 h). PARP, poly-ADP ribose polymerase

cells. We observed that SP600125 successfully inhibited phosphorylation of JNK, as well as its downstream target c-Jun, in response to both BFA and TNF (Figure 6a), and provided partial protection to necroptosis induced by both triggers (Figure 6b). Importantly, we observed that JNK activation was a result of TNFR1 signaling following BFA and TNF treatments. Indeed, TNFR1 repression by shRNA prevented BFA- and TNF-mediated phosphorylation of JNK and c-Jun (Figure $6 \mathrm{c}$ ), and resulted in the loss of the protective effect of SP600125 (Figure 6d). Nevertheless, we found that RIPK1 was not required for JNK activation (Figure 6e), and consequently that SP600125 also provided partial protection to apoptosis induced by TNF and BFA in the RIPK1-repressing cells (Figure 6f). Taken together, these results indicate that ER stress induction in L929sA cells activates ligand-independent TNFR1 signaling that mediates both RIPK1/RIPK3/MLKL-dependent necroptosis and RIPK1independent JNK-dependent death. 
a

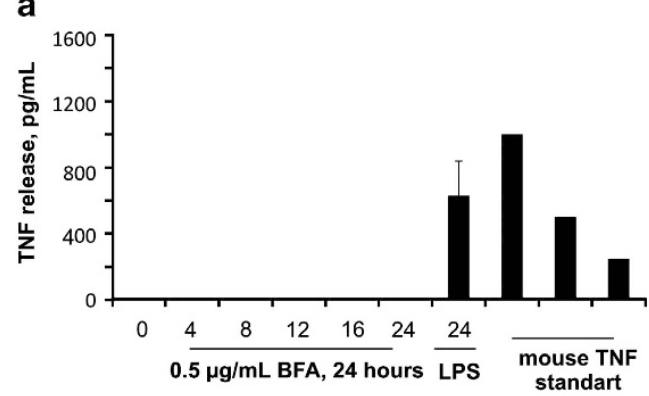

C

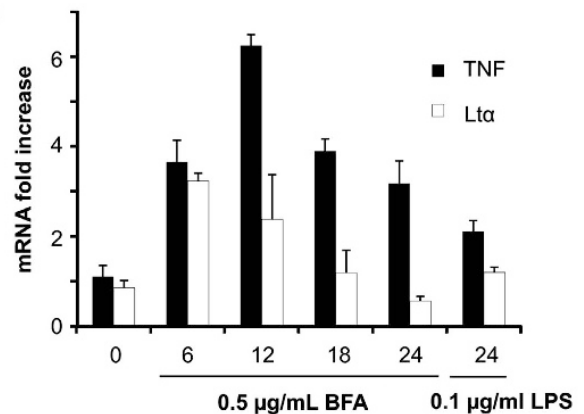

e

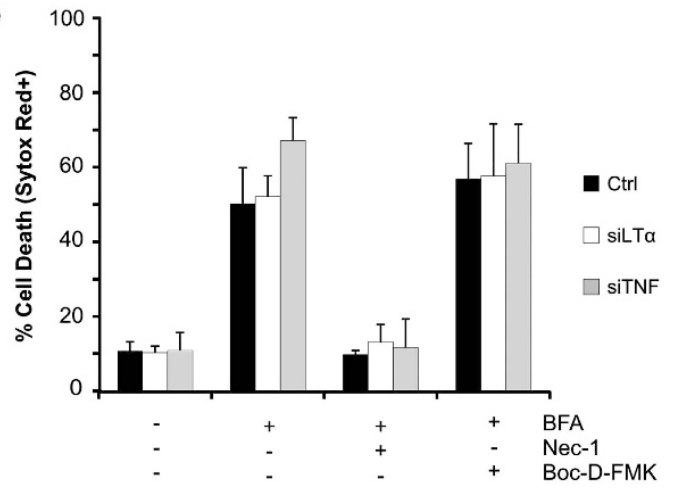

b

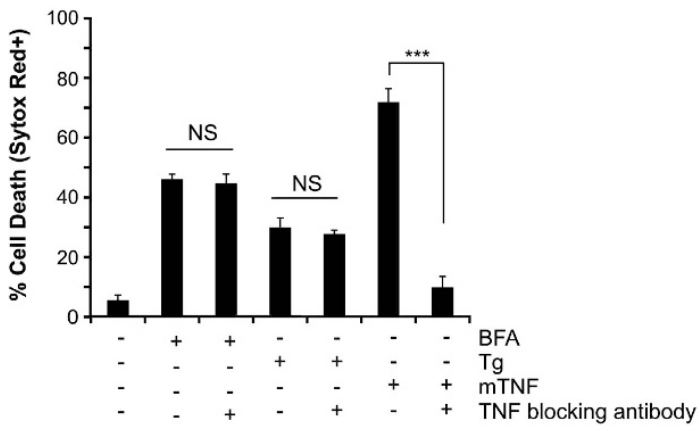

d
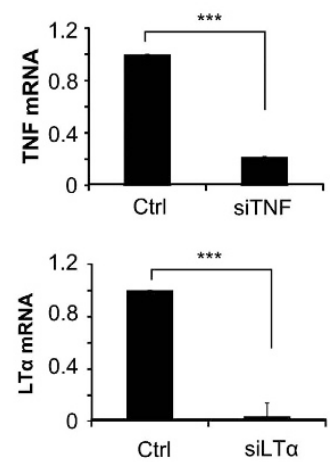

f
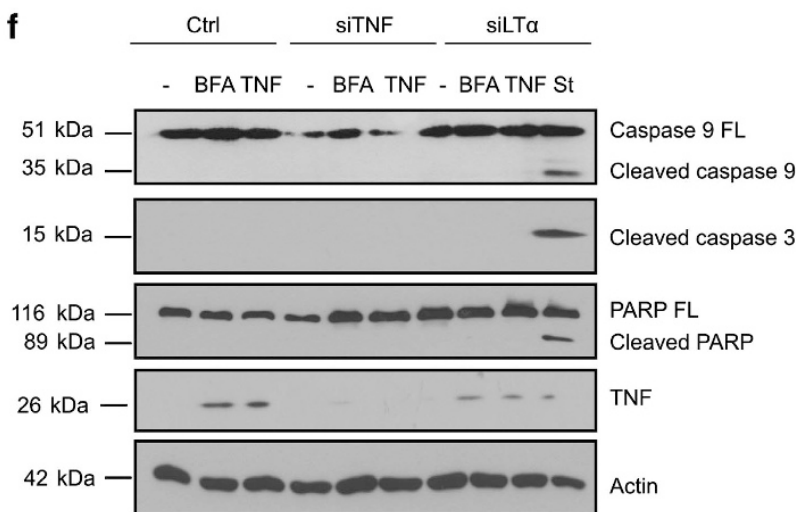

Figure 5 Role of TNFR1 ligands in ER stress-induced necroptosis. (a) The release of TNF in the medium after treatment with $0.5 \mu \mathrm{g} / \mathrm{ml}$ of brefeldin A (BFA) for indicated time points was measured by enzyme-linked immunosorbent assay (ELISA). As a control, L929sA cells were also treated with $0.01 \mu \mathrm{g} / \mathrm{ml}$ of lipopolysaccharide (LPS) for $24 \mathrm{~h}$. Mouse TNF standard was used for the standard curve. (b) L929sA cells were treated with $20 \mathrm{ng} / \mathrm{ml}$ of mTNF (12 h), $0.5 \mu \mathrm{g} / \mathrm{ml}$ of BFA (24 h) or $2.5 \mu \mathrm{M}$ of thapsigargin (Tg) $(24 \mathrm{~h})$ in the presence or absence of $12 \mathrm{ng} / \mathrm{ml}$ of TNF-blocking antibody. Viability was evaluated by flow cytometry following Sytox Red staining. (c) The induction of TNF and LT $\alpha$ mRNAs following treatment with $0.5 \mu \mathrm{g} / \mathrm{ml}$ of BFA for the indicated period of time was evaluated by quantitative PCR (Q-PCR) analysis. (d) Levels of TNF and LT $\alpha$ mRNA after short interfering RNA (siRNA)-mediated knockdown. (e) Control (Ctrl), TNF-depleted (siTNF) and LT $\alpha$-depleted (siLT $\alpha$ ) L929sA cells were stimulated for $24 \mathrm{~h}$ with $0.5 \mu \mathrm{g} / \mathrm{ml}$ of BFA in the absence or presence of $20 \mu \mathrm{M}$ of Nec-1 or $10 \mu \mathrm{M}$ of Boc-D-FMK, and cell viability was evaluated by flow cytometry following Sytox Red staining. (f) Immunoblots of Ctrl, TNFdepleted and LT $\alpha$-depleted L929sA cell lysates isolated after treatment for $24 \mathrm{~h}$ with $0.5 \mu \mathrm{g} / \mathrm{ml}$ of BFA or $4 \mathrm{~h}$ with $30 \mathrm{ng} / \mathrm{ml}$ of human TNF (hTNF). Cells treated with $10 \mathrm{nM}$ of staurosporine were used as Ctrl for apoptosis induction. NS, not significant; PARP, poly-ADP ribose polymerase

\section{Discussion}

Cell death is a crucial process for multicellular organisms, as it ensures proper morphogenesis, establishment of the immune system, elimination of damaged cells and maintenance of homeostasis. As a consequence, cell death needs to be tightly regulated because inappropriate cell death responses inexorably lead to the development of pathologies. In humans, these include neurodegenerative disorders, autoimmune diseases, diabetes and cancers. Apoptosis, a process relying on the activation of the caspase cascade, has long been considered the only form of regulated cell death, but existence of additional forms of controlled cell death is now well established. ${ }^{32,33}$ These can be triggered independently of apoptosis induction or as back-up safety mechanisms in situations where the apoptotic machinery does not operate properly, such as a result of genetic mutations or chemical/microbial inhibition.

Necroptosis, or programmed/regulated necrosis, is a nonapoptotic, caspase-independent, inflammatory type of cell death that relies on the enzymatic activity of RIPK $1 / 3$ and on the pseudokinase MLKL. ${ }^{14,15}$ Necroptosis has attracted a lot of attention lately because of its demonstrated role as alternative cell death modality during infection, ${ }^{34}$ as well as for its contribution to the pathogenesis of several human 
a

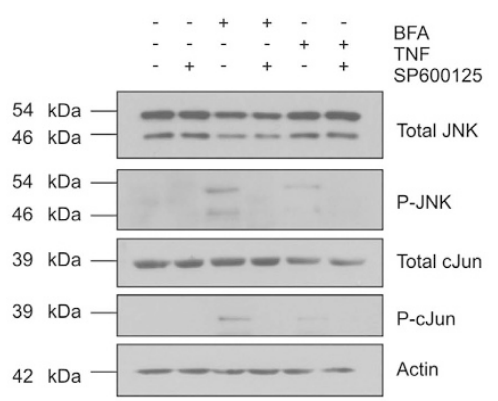

C

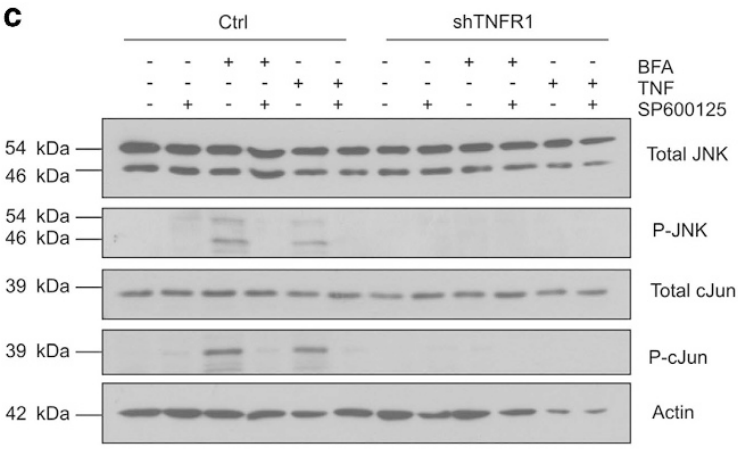

e
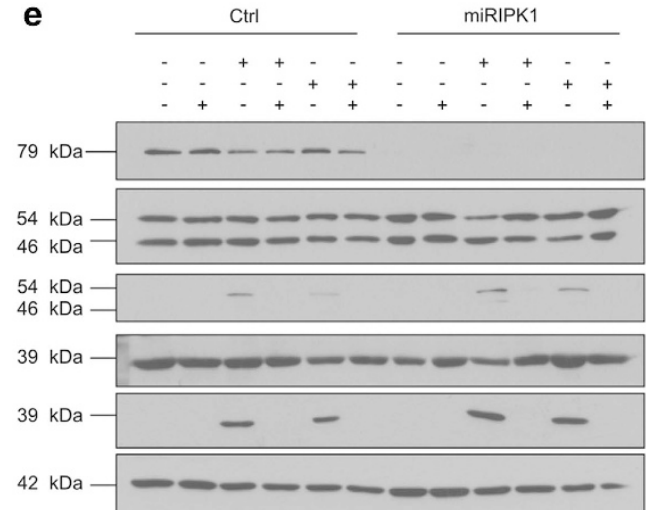

b

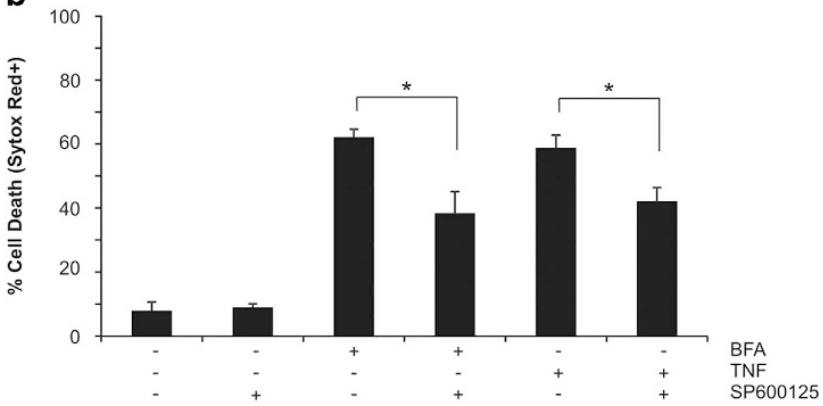

d
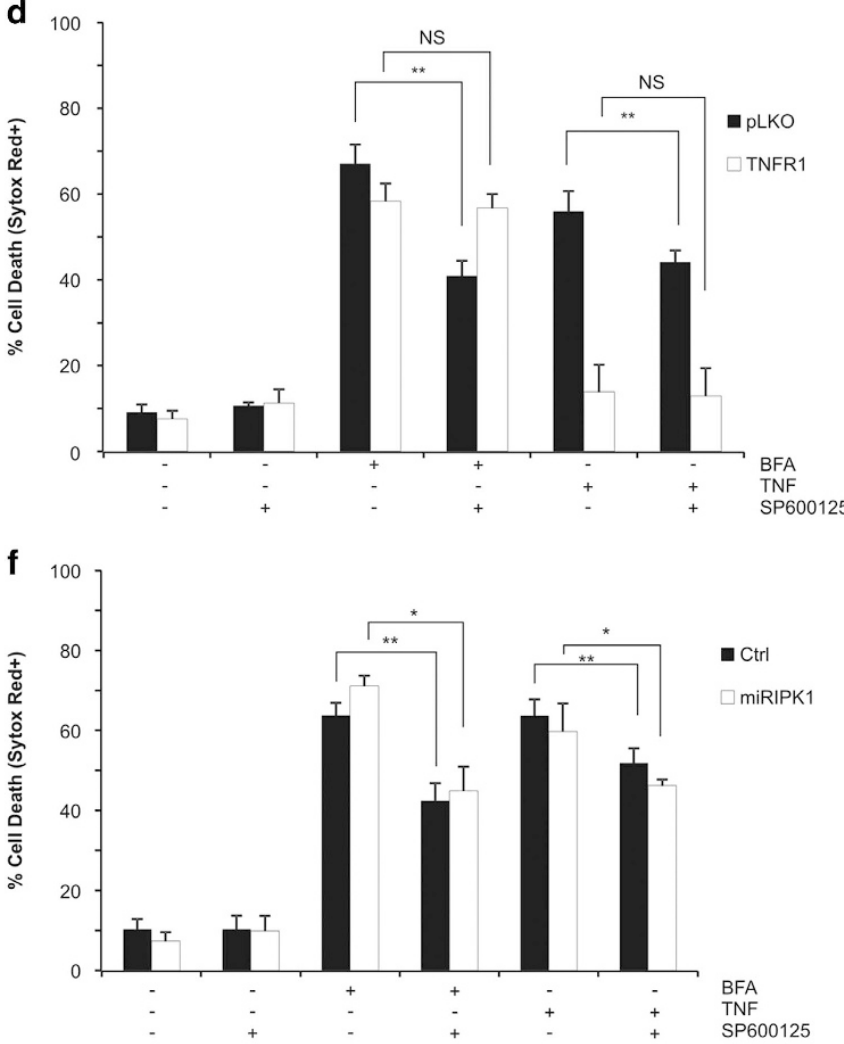

Figure 6 Role of JNK inhibition in ER stress-induced cell death. (a and b) L929sA cells and (c and d) control (Ctrl) and shTNFR1 L929sA cells were stimulated for $24 \mathrm{~h}$ with $0.5 \mu \mathrm{g} / \mathrm{ml}$ of brefeldin A (BFA) or $4 \mathrm{~h}$ with $30 \mathrm{ng} / \mathrm{ml}$ of human TNF (hTNF) in the absence or presence of $20 \mu \mathrm{M}$ of SP600125. (a and c) Cell lysates were immunoblotted as indicated and ( $\mathbf{b}$ and $\mathbf{d}$ ) cell viability was evaluated by flow cytometry following Sytox Red staining. (e and f) Control (Ctrl) and miRIPK1 L929sA cells stimulated for 24 $\mathrm{h}$ with $0.5 \mu \mathrm{g} / \mathrm{ml}$ of brefeldin A or with $30 \mathrm{ng} / \mathrm{ml}$ of hTNF (Ctrl cells were stimulated for $4 \mathrm{~h}$ and RIPK1-depleted cells for $2 \mathrm{~h}$ to induce a comparable amount of cell death) in the absence or presence of $20 \mu \mathrm{M}$ of SP600125. (e) Cells lysates were immunoblotled as indicated and (f) cell viability was evaluated by flow cytometry following Sytox Red staining

diseases, such as ischemic brain injury, myocardial infarction and stroke, renal ischemia-reperfusion injury, pancreatitis and inflammatory bowel diseases (for a review see Linkermann and Green $^{14}$ and Vanlangenakker et al. $^{35}$ ). Interestingly, conditions such as infection and hypoxia-ischemia are physiological ER stress inducers, and ER stress-induced cellular dysfunction and death have been associated with diseases that are known to be mediated, at least in part, by necroptosis. ${ }^{6,7}$ However, whether ER stress could directly trigger necroptosis had remained an open question. Indeed, studies in the ER stress field have so far mainly focused on the the ability of ER stress to kill by activating the intrinsic apoptotic pathway. ${ }^{4}$ In this study, we provide clear evidence that unresolved ER stress, induced by three different compounds, can also result in necroptosis induction, thus highlighting a potential molecular link between ER stress, necroptosis and the establishment of those diseases. In addition, the fact that ER stress can trigger an inflammatory type of cell death, which contrasts with apoptosis that is in many conditions immunosilent, opens doors for future studies on the role of ER stress in inflammation-driven pathologies.

In our cellular system, the L929sA cell line, we found that ER stress-induced necroptosis was mediated by TNFR1, which is in line with earlier studies implicating TNFR1 signaling in the cellular response to ER stress. ${ }^{26,28}$ As previously reported following TNF stimulation, ${ }^{19}$ we observed that RIPK1 kinase inhibition by Nec-1, or Nec-1s, protected L929sA cells from ER stress cytotoxicity while RIPK1 repression induced a switch to apoptosis. The plasticity in the cell death modality used was further highlighted by the switch back to RIPK1-independent 
necroptosis when caspases were additionally inhibited. Indeed, RIPK1-depleted L929sA cells could only be rescued from ER stress-induced death by the combination of caspase inhibition and RIPK3 repression. In contrast, MLKL repression induced a switch to apoptosis that could be inhibited by caspase inhibition, highlighting the more downstream role of MLKL in the necroptotic cascade. Importantly, the ability of the cells to adapt to an alternative cell death route was not only observed upon repression of a downstream executioner but also when knocking down the receptor itself. Indeed, a switch from necroptosis to apoptosis was also detected upon TNFR1 repression. Taken together, the results highlight the difficulty to block cell death under ER stress conditions owing to the ability of the cells to circumvent blockade of one specific pathway by activating alternative death routes. These findings are of major importance for the success of therapeutic strategies aimed at inhibiting ER stress-mediated death. In this context, our results show that $\mathrm{Nec}-1$ is a good candidate, as the allosteric inhibition of RIPK1 kinase activity does not allow a switch to another death mode. Moreover, these results also highlight the importance of proper cell death typing when evaluating the contribution of certain proteins in the death induced by ER stress.

Surprisingly, we found, using blocking antibody and RNAi approaches, that signaling by TNFR1 during ER stress was occurring independently of ligand binding. These results are in contrast with those from Hu et al. ${ }^{26}$ who suggested a model of ER stress-induced TNFR1 activation resulting from IRE1mediated NF- $\kappa$ B-dependent autocrine production of TNF. ${ }^{26}$ Nevertheless, our results support the study of Yang et al., ${ }^{28}$ which suggested ligand-independent activation of TNFR1 at the ER membrane during ER stress. ${ }^{28}$ Interestingly, ligandindependent signaling by TNFR1 at the ER was also recently reported in the case of TNF receptor-associated periodic syndrome (TRAPS), an autosomal-dominant autoinflammatory disease associated with heterozygous mutations in TNFR1. ${ }^{36}$ In this study, the authors showed that TRAPSassociated mutant TNFR1 molecules are retained in the ER and unable to bind TNF but still capable of signaling to NF-kB and to cell death. Of note, in our study, it is unknown whether the ER stress-induced ligand-independent TNFR1 signaling originates at the plasma membrane or intracellularly. However, knowing that severe ER stress conditions alter export of membrane proteins, it is reasonable to speculate that it also originates from intracellular compartments, and potentially from the ER. Of note, ER stress-induced ligand-independent DR5-mediated apoptosis has recently been reported in other cell types. ${ }^{37}$ This demonstrates the ability of ER stress to trigger ligand-independent activation of death receptors, whose identity may vary depending on the cell type.

Finally, we observed that activation of TNFR1 by ER stress or TNF stimulation in L929sA cells resulted in JNK activation, which partially contributed to necroptosis induced by these triggers. In contrast to the results of Yang et al., ${ }^{28}$ we found that RIPK1 repression had no impact on JNK activation, and that JNK inhibition still provided protection to apoptosis resulting from RIPK1 repression in these cells. The fact that JNK inhibition provided protection to both TNFR1-induced necroptosis and apoptosis is intriguing, and suggest a rather aspecific role of JNK in cell death induction in these cells.
In conclusion, our study reveals the ability of ER stress to trigger RIPK1 kinase-dependent necroptosis, which opens new doors for future work on the implication of ER stress in pathologies resulting from the inappropriate induction of this inflammatory type of cell death.

\section{Materials and Methods}

Cell culture and reagents. L929sA cells were cultured in Dulbecco's modified Eagle's medium (Sigma-Aldrich, St. Louis, MO, USA; D6429) with 10\% (v/v) fetal bovine serum, $1 \%(\mathrm{~V} / \mathrm{v})$ penicillin-streptomycin (Sigma-Aldrich; P0781) and $2 \mathrm{mM}$ L-glutamine (Sigma-Aldrich; G7513). HEK293T cells used for the viral production were grown in the same media but without the L-glutamine supplement. Cells were cultured in a humidified incubator at $37^{\circ} \mathrm{C}$ with a $5 \% \mathrm{CO}_{2}$ concentration. The reagents used for the treatments were as follows: human TNF (Immunotools, Friesoythe, Germany; no. 11343017), staurosporine (Sigma-Aldrich; no. S6942), brefeldin A (Sigma-Aldrich; no. B7651), tunicamycin (Sigma-Aldrich; no. T7765), thapsigargin (Sigma-Aldrich; no. T9033), Boc-D-FMK (Cambridge Bioscience, Cambridge, UK; no. 1120-20C), Nec-1 (Santa Cruz Biotechnology, Dallas, TX, USA; no. CAS 4311-88-0), RIP1 inhibitor II, 7-Cl-O-Nec-1 (Nec-1s) (Merck, Darmstadt, Germany; no. 504297) and SP600125 (Sigma-Aldrich; no. S5567). Recombinant mouse TNF is produced and purified to at least $99 \%$ homogeneity in our laboratory. The antibodies used in the study were as follows: PARP (CST, Danvers, MA, USA; no. 9542), caspase-9 (CST; no. 9508), cleaved caspase-3 (CST; no. 9665), actin (Sigma-Aldrich; no. A2066), RIPK1 (BD Transduction Laboratories, Franklin Lakes, NJ, USA; no. 610459), RIPK3 (Sigma-Aldrich; no. R4277), TNF (Santa Cruz Biotechnology; no. sc-52746), c-Jun (Santa Cruz Biotechnology; no. sc-1694), phospho-c-Jun (Santa Cruz Biotechnology; no. sc-822), SAPK/JNK (CST; no. 9252) and phospho-SAPK/JNK (CST; no. 9251). All the secondary antibodies were purchased from The Jackson Laboratory (Bar Harbor, ME, USA) and the signal was visualized using Western Lightning ECL substrates (Perkin-Elmer, Waltham, MA, USA). The TNF-blocking antibody comes from Bioceros BV (Utrecht, Netherland; no. XT-22). The mouse TNF ELISA Kit was purchased from eBioscience (San Diego, CA, USA; no. 88-7324-22) and used according to the manufacturer's protocol.

Gene repression. Control, miRIPK1 and miRIPK3 L929sA cells were generated as described previously. ${ }^{38} \mathrm{pLKO}$ lentiviral control and shRNA vector against mouse TNFR1 (TRCN0000066103) were obtained from Sigma-Aldrich. Lentivirus production was obtained by co-transfecting the lentiviral plasmids with the second-generation lentivirus packaging system (Addgene, Cambridge, MA, USA; pMD2.G cat. no. 12259, psPAX2 cat. no.12260, pRSV-Rev cat. no. 12253) using JET PEI transfection reagent (Polyplus Transfection, Illkirch, France; cat. no. 101-01N) into HEK293T cells. Viruscontaining supernatant was harvested and filtered through $0.22 \mu \mathrm{m}$ filter. Transduction was performed in the presence of $5 \mu \mathrm{g} / \mathrm{ml}$ of polybrene (Merck Millipore, Darmstadt, Germany; TR-1003-G). Control and shTNFR1 cells were selected for $72 \mathrm{~h}$ in $5 \mu \mathrm{g} / \mathrm{ml}$ of puromycin. TNF (L-042302-00-0005), LT $\alpha$ (L-043958-00-0005) and nonspecific (D-001810-01-20) siRNAs were purchased from Dharmacon (Thermo Fisher Scientific, Waltham, MA, USA). siRNA transfection was performed using INTERFERin (Polyplus Transfection; no. 409-50) according to the manufacturer's protocol.

RNA extraction, RT-PCR and Q-PCR. RNA was extracted using the TRIzol reagent (Sigma-Aldrich; no. T9424), precipitated with ethanol and reverse transcribed using the superscript III following the manufacturer's protocol (Invitrogen, Waltham, MA, USA). The obtained CDNA was used as template for the PCR reactions using the following primers: GAPDH (forward primer: $5^{\prime}$-ACCACAG TCCATGCCATC-3'; reverse primer: 5'-TCCACCACCCTGTTGCTG-3') and TNFR1 (forward primer: 5'-CAGTCTGCAGGGAGTGTGAA-3'; reverse primer: 5'-CACGCA CTGGAAGTGTGTCT-3') (Integrated DNA Technologies, Coralville, IA, USA).

Q-PCR was performed using Brilliant III Ultra-Fast Q-PCR Master Mix (Agilent, Santa Clara, CA, USA) according to the manufacturer's protocol. Relative gene expression was evaluated by $\triangle \triangle C T$ method and GAPDH was used as the housekeeping gene to normalize gene expression. Probes were purchased from Integrated DNA Technologies and were as follows: GAPDH (forward primer: 5'-GCCTTCCGTGTTCCTACC-3'; reverse primer: 5'-CCTCAGTGTAGCCCAAGAT G-3'), LT $\alpha$ (forward primer: 5'-TCTCCAGAGCAGTGAGTTCT-3'; reverse primer: 5'-CTCAGAAGCACTTGACCCAT-3'), TNF (forward primer: 5'-TCTTTGAGA TCCATGCCGTTG-3'; reverse primer: 5'-AGACCCTCACACTCAGATCA-3') and MLKL (forward primer: $5^{\prime}$-TCTCTCTGCTTTAGTGCTCTTTG-3'; reverse primer: 5'-CAGCTCCAGTTTCCTCGTAG-3'). 
DEVDase assay. Following stimulation, the cells were trypsinized, pelleted, washed once with PBS and resuspended in $50 \mu \mathrm{l}$ of ice-cold PBS. Samples were then snap-frozen in duplicate and kept at $-80^{\circ} \mathrm{C}$ until further processing. On the day of the assay, the samples were diluted in the assay buffer (100 mM HEPES, $10 \%$ sucrose and $0.1 \%$ CHAPS) in the presence of a final concentration of $50 \mu \mathrm{M}$ of Ac-Asp-Glu-Val-Asp- $\alpha$-(4-methyl-coumaryl-7-amide) (Peptide Institute Inc., Osaka, Japan; cat. no. $3171-\mathrm{v}), 0.0001 \% \mathrm{NP}-40$ and $5 \mu \mathrm{M}$ of DTT. The samples were then read at $355 \mathrm{~nm}$ excitation and $460 \mathrm{~nm}$ emission on a preheated plate reader (at $37^{\circ} \mathrm{C}$ ) for 30 cycles with 1 min intervals.

Cell death analysis. Following stimulation, the cells were trypsinized, pelleted, resuspended in PBS containing $5 \mathrm{nM}$ of Sytox Red (Invitrogen; no. S34859) and incubated for 15 min on ice. The cells were then analyzed for Sytox Red positivity using the BD FACs Canto Flow Cytometer (BD Bioscience, Franklin Lakes, NJ, USA). The percentage of cell death is calculated as follows: $\%$ cell death $=\left(\right.$ no. of Sytox Red $\left.{ }^{+}\right)$ (no. of Sytox $\operatorname{Red}^{+}+$no. of Sytox $\left.\left.\operatorname{Red}^{-}\right)\right) \times 100$.

Statistical analysis. Experiments were repeated independently at least three times. Error bars represent the standard deviation (S.D.) of replicates. Statistical analyses were performed using unpaired Student's $t$-tests using the GraphPad Software (San Diego, CA, USA) $\left({ }^{\star} P<0.05\right.$, ${ }^{\star \star} P<0.01$ and $\left.{ }^{* \star *} P<0.001\right)$.

\section{Conflict of Interest}

The authors declare no conflict of interest.

Acknowledgements. MB has a tenure track position within the Multidisciplinary Research Program of Ghent University (GROUP-ID). Research in the Vandenabeele unit is supported by Belgian grants (Interuniversity Attraction Poles, IAP 7/32), Flemish grants (Research Foundation Flanders, G.0875.11, G.0973.11, G.0A45.12N, G.0787.13N, G.0172.12N; Methusalem grant, BOF09/01M00709), Ghent University grants (MRP, GROUP-ID consortium), grant from the Foundation against Cancer (F94 and 2010-162) and grants from the VIB. Research in Samali group is conducted with the financial support of Science Foundation Ireland (Grant nos 06/RFP/BIC002 and 05/IN3/B851) and Health Research Board (Grant no. HRA_HSR/2010/24). SS is a recipient of a Thomas Crawford Hayes scholarship. AS is a co-founder and director at Aquita Bioscience Ltd.

1. Healy $S$, Verfaillie $T$, Jäger $R$, Agostinis $P$, Samali A. Biology of the endoplasmic reticulum. In: Agostinis P, Afshin S (eds). Endoplasmic Reticulum Stress in Health and Disease, 2012. Springer: Netherlands, pp 3-22.

2. Jäger R, Bertrand MJM, Gorman AM, Vandenabeele $P$, Samali $A$. The unfolded protein response at the crossroads of cellular life and death during endoplasmic reticulum stress. Biol Cell 2012; 104: 259-270.

3. Gorman AM, Healy SJM, Jäger R, Samali A. Stress management at the ER: regulators of ER stress-induced apoptosis. Pharmacol Ther 2012; 134: 306-316.

4. Hetz C. The unfolded protein response: controlling cell fate decisions under ER stress and beyond. Nat Rev Mol Cell Biol 2012; 13: 89-102.

5. Vincenz L, Jäger R, O'Dwyer M, Samali A. Endoplasmic reticulum stress and the unfolded protein response: targeting the achilles heel of multiple myeloma. Mol Cancer Ther 2013; 12: 831-843.

6. Hetz C, Chevet E, Harding HP. Targeting the unfolded protein response in disease. Nat Rev Drug Discov 2013; 12: 703-719.

7. Kim I, Xu W, Reed JC. Cell death and endoplasmic reticulum stress: disease relevance and therapeutic opportunities. Nat Rev Drug Discov 2008; 7: 1013-1030.

8. Szegezdi E, MacDonald DC, Ní Chonghaile T, Gupta S, Samali A. Bcl-2 family on guard at the ER. Am J Physiol 2009; 296: C941-C953.

9. Urano F, Wang X, Bertolotti A, Zhang Y, Chung P, Harding HP et al. Coupling of Stress in the ER to activation of JNK protein kinases by transmembrane protein kinase IRE1. Science 2000; 287: 664-666.

10. Upton J-P, Wang L, Han D, Wang ES, Huskey NE, Lim L et al. IRE1 $\alpha$ cleaves select microRNAs during ER stress to derepress translation of proapoptotic caspase-2. Science 2012; 338: 818-822.

11. Sandow JJ, Dorstyn L, O'Reilly LA, Tailler M, Kumar S, Strasser A et al. ER stress does not cause upregulation and activation of caspase-2 to initiate apoptosis. Cell Death Differ 2014; 21: 475-480.

12. Oyadomari S, Mori M. Roles of CHOP//GADD153 in endoplasmic reticulum stress. Cell Death Differ 2003; 11: 381-389.

13. Sano R, Reed JC. ER stress-induced cell death mechanisms. Biochim Biophys Acta 2013; 1833: 3460-3470.

14. Linkermann A, Green DR. Necroptosis. N Engl J Med 2014; 370: 455-465.
15. Vandenabeele P, Galluzzi L, Vanden Berghe T, Kroemer G. Molecular mechanisms of necroptosis: an ordered cellular explosion. Nat Rev Mol Cell Biol 2010; 11: 700-714.

16. O'Donnell MA, Perez-Jimenez E, Oberst A, Ng A, Massoumi R, Xavier R et al. Caspase 8 inhibits programmed necrosis by processing CYLD. Nat Cell Biol 2011; 13: 1437-1442.

17. Gunther C, Martini E, Wittkopf N, Amann K, Weigmann B, Neumann H et al. Caspase-8 regulates TNF-[agr]-induced epithelial necroptosis and terminal ileitis. Nature 2011; 477: 335-339.

18. Kaiser WJ, Upton JW, Long AB, Livingston-Rosanoff D, Daley-Bauer LP, Hakem R et al. RIP3 mediates the embryonic lethality of caspase-8-deficient mice. Nature 2011; 471: 368-372.

19. Vanlangenakker $\mathrm{N}$, Bertrand MJM, Bogaert $\mathrm{P}$, Vandenabeele $\mathrm{P}$, Vanden Berghe $T$. TNF-induced necroptosis in L929 cells is tightly regulated by multiple TNFR1 complex I and II members. Cell Death Dis 2011; 2: e230.

20. Remijsen Q, Goossens V, Grootjans S, Van den Haute C, Vanlangenakker N, Dondelinger Y et al. Depletion of RIPK3 or MLKL blocks TNF-driven necroptosis and switches towards a delayed RIPK1 kinase-dependent apoptosis. Cell Death Dis 2014; 5: e1004.

21. Humphreys DT, Wilson MR. Modes of L929 cell death induced by TNF- $\alpha$ and other cytotoxic agents. Cytokine 1999; 11: 773-782.

22. Sun L, Wang H, Wang Z, He S, Chen S, Liao D et al. Mixed lineage kinase domain-like protein mediates necrosis signaling downstream of RIP3 kinase. Cell 2012; 148: 213-227.

23. Zhao J, Jitkaew S, Cai Z, Choksi S, Li Q, Luo J et al. Mixed lineage kinase domain-like is a key receptor interacting protein 3 downstream component of TNF-induced necrosis. Proc Natl Acad Sci USA 2012; 109: 5322-5327.

24. Murphy James M, Czabotar Peter E, Hildebrand Joanne M, Lucet Isabelle S, Zhang J-G, Alvarez-Diaz $S$ et al. The pseudokinase MLKL mediates necroptosis via a molecular switch mechanism. Immunity 39: 443-453.

25. Wu J, Huang Z, Ren J, Zhang Z, He P, Li Y et al. Mlkl knockout mice demonstrate the indispensable role of Mlkl in necroptosis. Cell Res 2013; 23: 994-1006.

26. Hu P, Han Z, Couvillon AD, Kaufman RJ, Exton JH. Autocrine tumor necrosis factor alpha links endoplasmic reticulum stress to the membrane death receptor pathway through IRE $1 \alpha$-mediated NF-kB activation and down-regulation of TRAF2 expression. Mol Cell Biol 2006; 26: 3071-3084.

27. Etemadi N, Holien JK, Chau D, Dewson G, Murphy JM, Alexander WS et al. Lymphotoxin $\alpha$ induces apoptosis, necroptosis and inflammatory signals with the same potency as tumour necrosis factor. FEBS J 2013; 280: 5283-5297.

28. Yang $Q$, Kim YS, Lin Y, Lewis J, Neckers L, Liu ZG. Tumour necrosis factor receptor 1 mediates endoplasmic reticulum stress-induced activation of the MAP kinase JNK. EMBO Rep 2006; 7: 622-627.

29. Liu J, Lin A. Role of JNK activation in apoptosis: a double-edged sword. Cell Res 2005; 15: 36-42

30. Ventura J-J, Cogswell P, Flavell RA, Baldwin AS, Davis RJ. JNK potentiates TNF-stimulated necrosis by increasing the production of cytotoxic reactive oxygen species. Genes Dev2004; 18: 2905-2915.

31. Bennett BL, Sasaki DT, Murray BW, O'Leary EC, Sakata ST, Xu W et al. SP600125, an anthrapyrazolone inhibitor of Jun N-terminal kinase. Proc Natl Acad Sci USA 2001; 98 : 13681-13686.

32. Tait SWG, Ichim G, Green DR. Die another way -n on-apoptotic mechanisms of cell death. J Cell Sci 2014; 127: 2135-2144.

33. Berghe TV, Linkermann A, Jouan-Lanhouet S, Walczak H, Vandenabeele P. Regulated necrosis: the expanding network of non-apoptotic cell death pathways. Nat Rev Mol Cell Biol 2014; 15: 135-147.

34. Sridharan H, Upton JW. Programmed necrosis in microbial pathogenesis. Trends Microbiol 22: 199-207.

35. Vanlangenakker N, Berghe TV, Krysko DV, Festiens N, Vandenabeele P. Molecular mechanisms and pathophysiology of necrotic cell death. Curr Mol Med 2008; 8: 207-220.

36. Lobito AA, Kimberley FC, Muppidi JR, Komarow H, Jackson AJ, Hull KM et al. Abnorma disulfide-linked oligomerization results in ER retention and altered signaling by TNFR1 mutants in TNFR1-associated periodic fever syndrome (TRAPS). Blood 2006; 108: 1320-1327.

37. Lu M, Lawrence DA, Marsters S, Acosta-Alvear D, Kimmig P, Mendez AS et al. Opposing unfolded-protein-response signals converge on death receptor 5 to control apoptosis. Science 2014; 345: 98-101.

38. Dondelinger Y, Aguileta MA, Goossens V, Dubuisson C, Grootjans S, Dejardin E et al. RIPK3 contributes to TNFR1-mediated RIPK1 kinase-dependent apoptosis in conditions of CIAP1/2 depletion or TAK1 kinase inhibition. Cell Death Differ 2013; 20: 1381-1392.

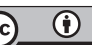

Cell Death and Disease is an open-access journal published by Nature Publishing Group. This work is licensed under a Creative Commons Attribution 4.0 International Licence. The images or other third party material in this article are included in the article's Creative Commons licence, unless indicated otherwise in the credit line; if the material is not included under the Creative Commons licence, users will need to obtain permission from the licence holder to reproduce the material. To view a copy of this licence, visit http://creativecommons.org/licenses/by/4.0 